\title{
NOTES
}

\section{SELECTIVE ADSORPTION OF SERUM PROTEINS TO AEROSIL}

Since Cohn's cold ethanol method was introduced into routine practice of plasma fractionation in this country, little attention has been paid to other approaches for isolating or fractionating plasma proteins, at least in the level of industrial production. Recently, however, in Western European countries, usefulness of selective adsorption of plasma proteins to various adsorbents is attracting renewed interest as mentioned by Schwick (1973, personal communication). According to Stephan (1971), aerosil, an aggregated form of $\mathrm{SiO}_{2}$, could be used as a selective adsorbent for serum lipoproteins which would otherwise affect the stability of the serum causing cloudiness. and deposit formation upon storage. By eliminating lipoproteins by the aerosil treatment, he improved considerably the stability of the serum. This study aimed to see the effect of the aerosil treatment on quantity as well as functions of various protein fractions of human sera.

Blood samples collected from apparently healthy donors, but being positive in the serological test for HB-antigen, were kindly supplied by Dr. S. Ōbayashi of the Japanese Red Cross Ōta Blood Center. To recalcified plasma further treated by conveying through a tubing of an ion-exchange collection set (Fenwal JB-2 BloodPack) to remove excess calcium ion, aerosil (obtained from the Japan Aerosil, Co., Ltd., Tokyo) was added to a final concentration of $2 \%(\mathrm{w} / \mathrm{v})$. The mixture was then stirred in a water-bath at $37 \mathrm{C}$ for $4 \mathrm{hr}$ and then centrifuged at $3,500 \mathrm{rpm}$ for 15 min. The supernatant was separated to serve as an aerosil-treated sample.

The relative content of plasma proteins (in w/w\%) was determined by electrophoresis on cellulose acetate film. The decrease in serum albumin was not significant, whereas globulins, especially $\beta$-globulin, decreased markedly by the aerosil treatment. When the absolute quantity was calculated from the total protein contents (determined by measuring optical density at $280 \mathrm{~nm}$ ), it was found that $\beta$-globulin had decreased from 7.35 to $4.20 \mathrm{mg} / \mathrm{ml}$ by the first, and to $4.12 \mathrm{mg} / \mathrm{ml}$ by the second treatment. These results are in good agreement with those reported by Stephan (1971).

A further attempt was made to determine by the single radial immunodiffusion technique the amounts of several serum protein fractions in the $\beta$-globulin region before and after the aerosil treatment. Commercially available plates containing specific antibodies (Partigen, Behringwerke) were used for this purpose. As seen in Table I, $\beta$-lipoprotein, plasminogen and $\beta_{2}$-glycoprotein I contents were greatly reduced, whereas hemopexin and transferrin were practically unaffected. $\beta_{1 A^{-}}$and $\beta_{1 E^{-}}$ globulins were gradually removed by two consecutive treatments with aerosil.

It is well known that HB-antigen contained in human serum comes close to the $\beta$-globulin fraction during the fractionation process. By Duimel, Brummelhuis and Krijnen (1972), adsorption to aerosil was used in purification of HB-antigen. In our study, after two consecutive treatments HB-antigen-positive serum turned to negative by radioimmunoassay as well as by the hemagglutination inhibition test (Table II). 
TABLE I

Removal of serum proteins in $\beta$-area by aerosil treatment

\begin{tabular}{lccc}
\hline \multirow{2}{*}{ Protein } & Untreated & \multicolumn{2}{c}{ Treated } \\
\cline { 3 - 4 } & & $1 \times$ & $2 \times$ \\
\hline B-lipoprotein & $340 \mathrm{mg} / \mathrm{dl}$ & $<100 \mathrm{mg} / \mathrm{dl}$ & $<100 \mathrm{mg} / \mathrm{dl}$ \\
$\boldsymbol{\beta}_{1 \text { A-globulin }}$ & 65 & 26 & $<10$ \\
Hemopexin & 67 & 56 & 40 \\
$\boldsymbol{\beta}_{1 \mathrm{E}}$-globulin & 30 & 6.0 & $0^{*}$ \\
Transferrin & 250 & 230 & 220 \\
Plasminogen & 38 & $<5$ & $0^{*}$ \\
$\boldsymbol{\beta}_{2}$-glycoprotein I & 24 & $0^{*}$ & $0^{*}$ \\
\hline
\end{tabular}

* No precipitation was observed.

TABLE II

Elimination of $H B$ antigen by aerosil treatment

\begin{tabular}{lrcc}
\hline \multirow{2}{*}{$\begin{array}{c}\text { Method for } \\
\text { determination }\end{array}$} & Before adsorption & \multicolumn{2}{c}{ After adsorption } \\
\cline { 3 - 4 } & & $1 \times$ & $2 \times$ \\
\hline $\begin{array}{l}\text { Healthy carrier } \\
\text { RIA }\end{array}$ & + & + & - \\
HI & 128 & 16 & $<2$ \\
Acute hepatitis patient & & & \\
RIA & + & + & - \\
HI & 256 & 16 & $<2$ \\
\hline
\end{tabular}

A considerable antigenicity was still present after the first treatment. Then, by the second treatment, HB-antigen was significantly eliminated in contrast to a less decrease in $\beta$-globulin than that caused by the first treatment.

Since the decrease in $\gamma$-globulin content resulted from the aerosil treatment seemed insignificant, it was attempted to see if titres of various antibodies were affected by the treatment. Sera used for these purposes were supplied by the courtesy of Dr. K. Nambu of the Juntendo University Hospital. Naturally-occurring blood-group antibodies and R. A. factor, both of which are thought to belong mainly to IgM, were unaffected by the treatment. A slight decrease in the titer of antistreptolysin $\mathrm{O}$, namely from $1: 320$ to $1: 240$, was observed only with the conventional haemolysis in hibition technique, whereas the titer in the latex agglutination test employing a test kit supplied by Behringwerke remained unaffected. Such a disagreement may have been due to the involvement of nonspecific effect of increased $\alpha_{2^{-}}$and $\beta$-lipoproteins in a test sample upon the titer by the haemolysis inhibition technique as pointed out (Winblad, 1966; Killander, Philipson and Winblad, 1965). 
TABLE III

Influence of aerosil treatment on biochemical activities of serum of an acute hepatitis patient

\begin{tabular}{lll}
\hline \multicolumn{1}{c}{ Item } & Before & After \\
\hline Total bilirubin & $6.5 \mathrm{mg} / \mathrm{dl}$ & $2.3 \mathrm{mg} / \mathrm{dl}$ \\
Direct bilirubin & 1.8 & 1.1 \\
Indirect bilirubin & 4.7 & 1.2 \\
TTT & $5.30 \mathrm{U}$ & $0.79 \mathrm{U}$ \\
ZTT & 10.8 & 8.3 \\
GOT & 330 & 300 \\
GPT & 370 & 280 \\
A1-P & 10.5 & 7.0 \\
LDH & 360 & 300 \\
LAP & 240 & 210 \\
$\gamma$-GTP & 66 & 14.2 \\
\hline
\end{tabular}

Effect of the aerosil treatment upon the results of some liver function tests was also studied (Table III). In contrast to relatively slight decrease in values of glutamic oxaloacetic transaminase (GOT), glutamic pyruvic transaminase (GPT), alkaline phosphatase (A1-P), lactic dehydrogenase (LDH), leucine aminopeptidase (LAP) and zinc sulfate turbidity test (ZTT), marked lowering in values of thymol turbidity test (TTT), $r$-glutamyltranspeptidase $(r$-GTP) as well as in indirect bilirubin level were observed.

As for C-reactive protein (CRP), reduction in height of precipitates from $4 \mathrm{~mm}$ $(4+)$ to $2 \mathrm{~mm}(2+)$ was observed by a single treatment with aerosil.

When human plasma, instead of serum, was treated with aerosil, the supernatant was found no longer clottable on addition of thrombin. On the other hand, when human plasma deprived of prothrombin and factors VII, IX, X, etc. by adsorption with alminium hydroxide was added to the aerosil-treated plasma it was still clottable. Thus, the aerosil treatment seems to have eliminated fibrinogen leaving prothrombin in the supernatant.

Our study not only confirmed selective adsorbing effect of aerosil upon some serum proteins in the $\beta$-globulin region, but also determined the degree in reduction of several components that can be measured by the single radial immunodiffusion technique. Although there had been some studies on the availability of aerosil treatment in purification of HB-antigen, we further studied the reduction of HB-antigen by radioimmunoassay. Of course, we have no intention of stating that this treatment can provide us with serum preparations completely free from potential risk of transmitting hepatitis. Until a reliable test method for propagating type B-hepatitis agent becomes available, no absolute safeguard against such risks can be attained. We demonstrated that HB-antigen content was reduced to a level no longer detectable by radioimmunoassay, the most sensitive technique thus far available. Further 
advantages of this procedure are that it has little effect on antibody titers and on some of the enzymatic activities so far studied by ourselves, and that it would make serum preparations stable.

Adsorption to aerosil may not be the best method of purification of HB-antigen, because of some difficulty in eluting the adsorbed HB-antigen. Adsorption of HBantigen to concanavalin $\mathrm{A}$, instead of aerosil, and subsequent elution therefrom are now undertaken, the results of which will be published elsewhere.

\section{REFERENCES}

Duimel, W. J. M., Brummelhuis, H. G. J. And KRijnen, H. W. (1972): The purification of hepatitis-associated antigen (HAA/SH/AU) from human serum and the preparation of a sheep anti-HAA serum. Vox Sang., 23, 249-255.

Killander, J., Philipson, L. AND Winblad, S. (1965): Studies on non-specific antistreptolysin $\mathrm{O}$ titer. 2. Comparison of specific and non-specific antistreptolysins by gel filtration and dextran sulphate precipitation. Acta Path. Microb. Scand., 65, 587-596.

StEPHAN, W. (1971): Hepatitis-free and stable human serum for intravenous therapy. Vox Sang., $20,442-457$.

WINBLAD, S. (1966): Studies on non-specific antistreptolysin O titer. 1. The influence of serum $\beta$-lipoproteins on the non-specific antistreptolysin O titer. Acta Path. Microb. Scand;, $66,93-104$.

Department of General Biologics Control, HIROSHI ISHIYAMA National Institute of Health, JUNICHI YASUDA

Shinagawa-ku, Tokyo 141, and

Department of Research, HIROYOSHI ITO

Hokkaido Red Cross Blood Center,

Chuo-ku, Sapporo 064, Japan

(Received: May 17, 1974) 